\title{
Data Repository of Paper:
}

\section{The role of subducted sediments in plate interface dynamics as constrained by Andean forearc (paleo)topography}

\author{
Nicolás J. Cosentino $^{1 *}$, Felipe Aron ${ }^{2,3}$, Jorge G. F. Crempien ${ }^{2,3}$, Teresa E. Jordan ${ }^{1}$ \\ ${ }^{1}$ Department of Earth and Atmospheric Sciences, Cornell University, 2122 Snee Hall, Ithaca, NY \\ 14853-1504, USA \\ ${ }^{2}$ Departamento de Ingeniería Estructural y Geotécnica, Pontificia Universidad Católica de Chile, \\ Vicuña Mackenna 4860, Macul, Santiago, Chile \\ ${ }^{3}$ Centro de Investigación para la Gestión Integrada del Riesgo de Desastres (CIGIDEN), Vicuña \\ Mackenna 4860, Macul, Santiago, Chile \\ (*) e-mail: njc58@cornell.edu
}

\section{DR Section 1. Latitudinal topographic swath profiles of the forearc}

Latitudinal swath profiles were performed across straight segments every $0.01^{\circ}$ latitude, based on the method described by Hergarten et al. (2014) and with thicknesses such that they cover the entirety of the mapped CC and CD units. In each of these units' cases, the DEM outside the mapped area was set to Not a Number in order to better isolate their elevations. Swath data values are smoothed by averaging across a $1^{\circ}$-latitude-wide moving window.

\section{DR Section 2. Megathrust seismicity depth parameters}

To develop the high spatial resolution data for the six large earthquakes recorded since 1995, we used the finite fault slip distributions of the megathrust earthquakes published by the National Earthquake Information Center (NEIC) of the United States Geological Survey (https://earthquake.usgs.gov/earthquakes/). We projected the inverted slip across the fault on the subduction interface defined by the Slab1.0 model (Hayes et al., 2012) for all earthquakes greater than $\mathrm{M}_{\mathrm{w}} 7.5$ within the Chilean plate boundary. With the projected slip on the subduction interface, we computed the $25^{\text {th }}$ and $75^{\text {th }}$ percentiles of slip-weighted depth distribution over $0.5^{\circ}$-wide latitudinal swaths (see Data Repository Section 3), covering the entire latitudinal extent of our study area. Though a limited record, this computation provides an estimate of where subduction earthquakes tend to concentrate the maximum release of slip along the down-dip extension of the megathrust surface. The identified six events in the catalog correspond to the following earthquakes: (i) the $1995 \mathrm{M}_{\mathrm{w}} 8.0$ Antofagasta earthquake, (ii) $2007 \mathrm{M}_{\mathrm{w}} 7.7$ Tocopilla earthquake, (iii) $2010 \mathrm{M}_{\mathrm{w}} 8.8$ Maule earthquake, (iv) $2014 \mathrm{M}_{\mathrm{w}} 8.2$ Iquique earthquake and (v) its large $\mathrm{M}_{\mathrm{w}} 7.7$ subduction aftershock, and (vi) the 2015 $\mathrm{M}_{\mathrm{w}} 8.3$ Illapel earthquake (Hayes, 2017) (see Data Repository Figure DR1). Other possible finite slip distributions for those events have been published (e.g., Delouis et al., 2010; Lorito et al., 2011; 
Luttrell et al., 2011; Pollitz et al., 2011), including the $1985 \mathrm{M}_{\mathrm{w}} 8.0$ Valparaiso earthquake (Mendoza et al., 1994), which is not provided by the NEIC catalog. However, we reduced our analysis to the USGS data set, whose fault slip inversions share the same methodology of Ji et al. (2002), so as to maintain consistency.

We then complemented and expanded the analysis of slip depth concentration by looking at the ISC-GEM international seismic catalog (http://www.isc.ac.uk/iscbulletin/search/catalogue/). We selected all the events since 1900 whose centroid locations fall within the slab volume (Hayes et al., 2012) and so are more likely associated to subduction earthquakes. We also discriminate by focal mechanism (when these data are available), selecting only thrust earthquakes.

The surface described by Slab 1.0 was subdivided in several earthquake sub-faults of $0.1^{\circ}$. On each sub-fault, we assigned the closest interface subduction earthquakes and summed all their seismic moments to the particular sub-fault (see Data Repository Figure DR2). For earthquakes larger than the area of the sub-fault, we used the relationship of Allen and Hayes (2017) to determine the source dimensions of length and width. We then distributed uniformly the seismic moment in the sub-faults, such that the center of the uniformly distributed seismic moment of the earthquake was located right on the centroid location given by the ISC-GEM catalogue. We then defined $1^{\circ}$-wide swaths, parallel to the trench, where we computed the seismic-moment-weighted median depth (see Data Repository Section 3 ). Because of the nature of seismic moment, large earthquakes dominate the statistics. The result is that it is not possible to determine the $25^{\text {th }}-75^{\text {th }}$ percentiles as in the previous case of slip distributions for inverted earthquake data.

\section{DR Section 3. Weighted median and $25^{\text {th }}-75^{\text {th }}$ percentiles calculation}

We computed slip and moment-weighted $25^{\text {th }}-75^{\text {th }}$ percentiles of depth to evaluate if subduction earthquakes along the studied plate boundary show latitudinal variations of the seismicity depth distribution on the megathrust interface. Using finite slip models from the NEIC catalog and earthquake source parameters form the ISC-GEM catalog we defined $1^{\circ}$-wide latitudinal swaths where we computed the weighted $25^{\text {th }}-75^{\text {th }}$ percentiles depth (see DR Section 2). This was accomplished by finding the $\mathrm{k}^{\text {th }}$ value of depth $d_{i}$, such that the conditions stated in the following equation are satisfied:

$$
\left\{\begin{array}{l}
\sum_{i=1}^{k-1} w_{i} \leq \frac{1}{4} ; \frac{1}{2} ; \frac{3}{4} \\
\sum_{i=k}^{n} w_{i} \leq \frac{3}{4} ; \frac{1}{2} ; \frac{1}{4}
\end{array}\right.
$$

In this equation, the normalized weight $w_{i}$ equals the total slip or seismic moment release for each sub-fault within the swath. Because of the nature of seismic moment, large earthquakes dominate the statistics, making it difficult to determine $25^{\text {th }}-75^{\text {th }}$ percentiles as with the case of slip distributions for inverted earthquake data. 


\section{Supporting figures}

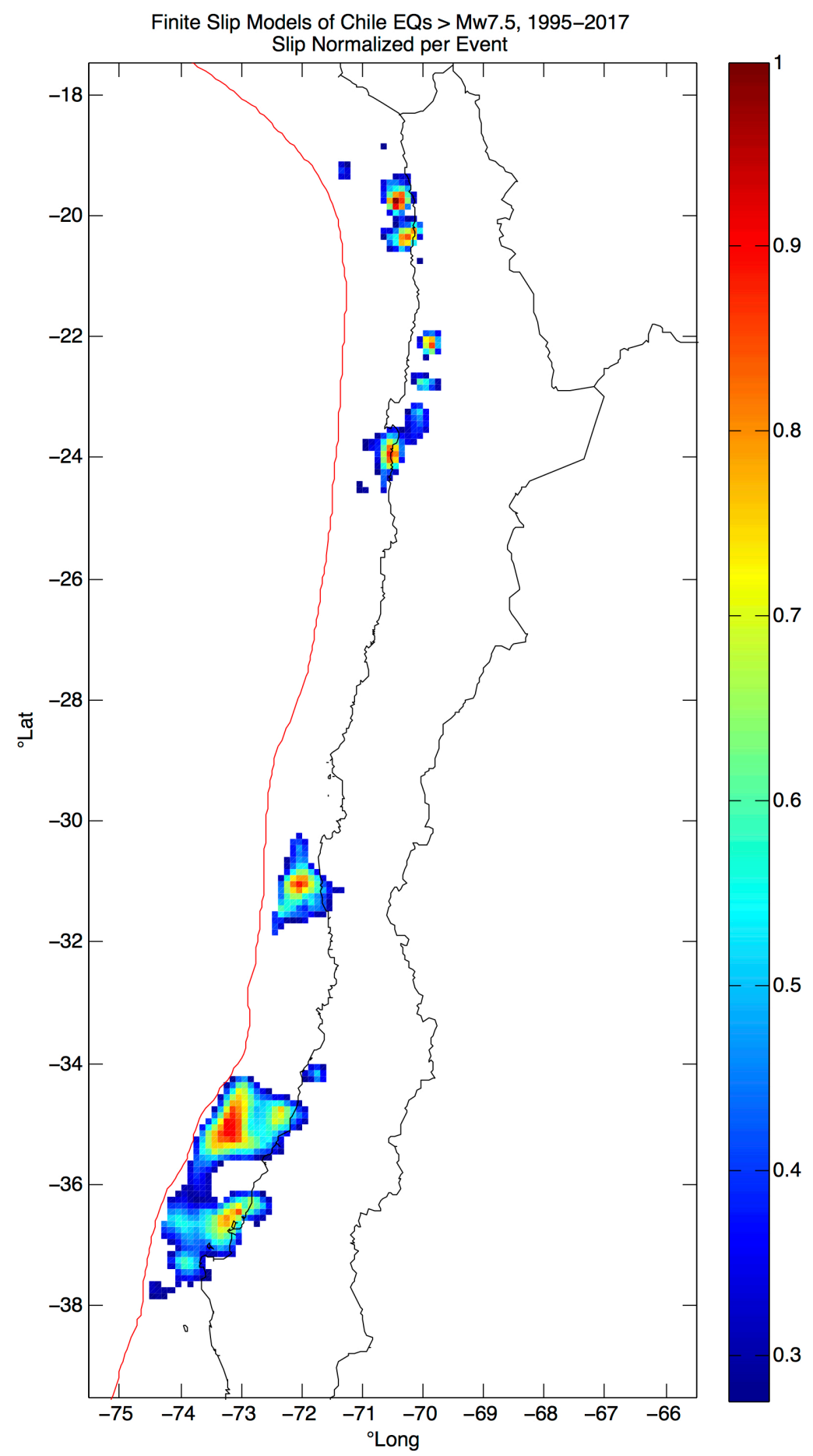

Figure DR1: Location of finite slip models of large-to-great subduction earthquakes $(\mathrm{Mw} \geq 7.5)$ that occurred in the study area of the Chilean plate boundary since 1995. Slip values are normalized by maximum slip per event. Red curve outlines the trench axis. Models from NEIC catalog (see main text). 


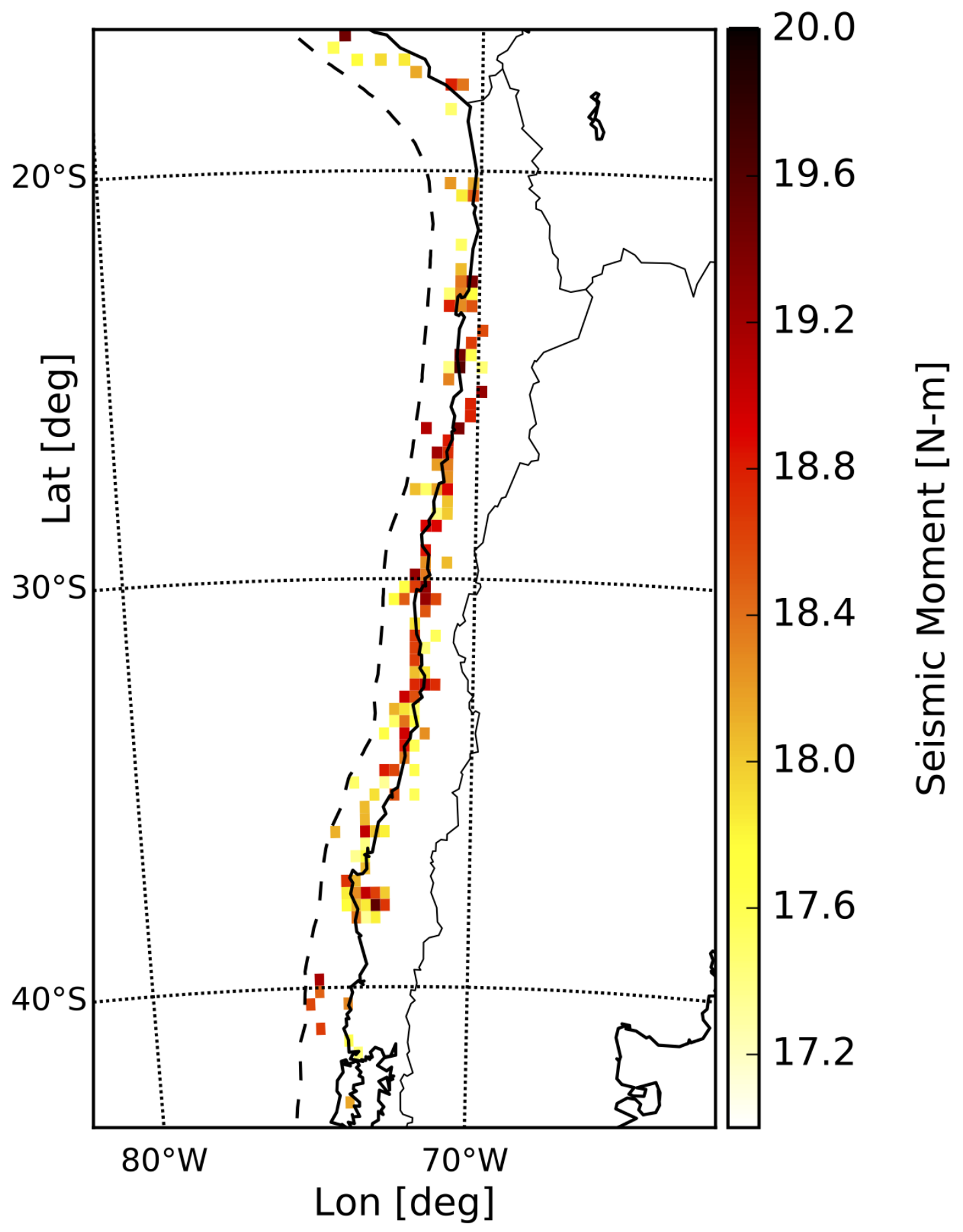

Figure DR2: Summed seismic moment of all earthquakes from the ISC-GEM catalog (see main text) projected onto the Slab 1.0 surface (Hayes et al., 2012) over $0.1^{\circ}$ sub-faults. At each grid element we assigned the closest interface subduction earthquakes and summed all their seismic moments to the particular sub-fault. Black dashed curve outlines the trench axis. 


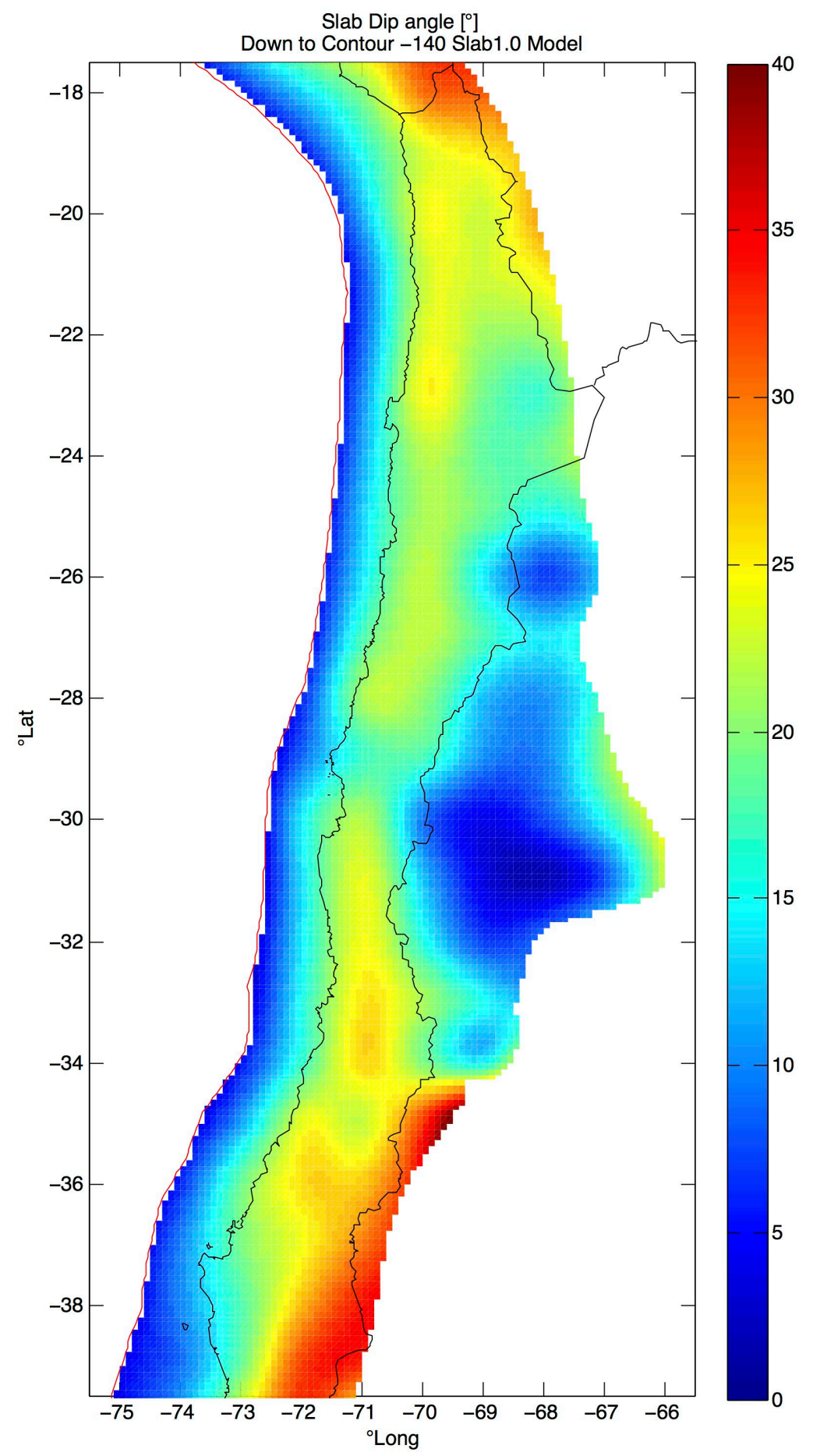

Figure DR3: Dip (in degrees) of the Nazca-South America plate boundary from the Slab1.0 model (Hayes et al., 2012) down to the $-140 \mathrm{~km}$ depth contour. Red curve outlines the trench axis. 


\section{REFERENCES CITED}

Allen, T.I., and Hayes, G.P., 2017, Alternative rupture-scaling relationships for subduction interface and other offshore environments: Bulletin of the Seismological Society of America, v. 107, no. 3, p. 1240-1253, https://doi.org/10.1785/0120160255.

Delouis, B., Nocquet, J.M., and Vallée, M., 2010, Slip distribution of the February 27, $2010 \mathrm{Mw}=8.8$ Maule earthquake, Central Chile, from static and high-rate GPS, InSAR, and broadband teleseismic data: Geophysical Research Letters, v. 37, L17305, https://doi.org/10.1029/2010GL043899.

Hayes, G.P., 2017, The finite, kinematic rupture properties of great-sized earthquakes since 1990: Earth and Planetary Science Letters, v. 468, p. 94-100, https://doi.org/10.1016/j.epsl.2017.04.003.

Hayes, G.P., Wald, D.J., and Johnson, R.L., 2012, Slab1.0: A three-dimensional model of global subduction zone geometries: Journal of Geophysical Research: Solid Earth, v. 117(B1), B01302-, doi:10.1029/2011JB008524.

Hergarten, S., Robl, J., and Stüwe, K., 2014, Extracting topographic swath profiles across curved geomorphic features: Earth Surface Dynamics, v. 2, p. 97-104, https://doi.org/10.5194/esurf-297-2014.

Ji, C., Wald, D.J., and Helmberger, D.V., 2002, Source Description of the 1999 Hector Mine, California, Earthquake, Part I: Wavelet Domain Inversion Theory and Resolution Analysis: Bulletin of the Seismological Society of America, v. 92, p. 1192-1207, https://doi.org/10.1785/0120000916.

Lorito, S., Romano, F., Atzori, S., Tong, X., Avallone, A., McCloskey, J., Cocco, M., Boschi, E., and Piatanesi, A., 2011, Limited overlap between the seismic gap and coseismic slip of the great 2010 Chile earthquake: Nature Geoscience, v. 4, p. 173-177, https://doi.org/10.1038/ngeo1073.

Luttrell, K.M., Tong, X., Sandwell, D.T., Brooks, B.A., and Bevis, M.G., 2011, Estimates of stress drop and crustal tectonic stress from the 27 February 2010 Maule, Chile, earthquake: Implications for fault strength: Journal of Geophysical Research. Solid Earth, v. 116, B11, p. 1978-2012.

Mendoza, C.S., Hartzell, S., and Monfret, T., 1994, Wide-band analysis of the 3 March 1985 Central Chile earthquake - overall source process and rupture history: Bulletin of the Seismological Society of America, v. 84, no. 2, p. 269-283.

Pollitz, F.F., Brooks, B., Tong, X., Bevis, M.G., Foster, J.H., Bürgmann, R., Smalley, R., Vigny, C., Socquet, A., Ruegg, J.C., and Campos, J., 2011, Cosesimic slip distribution of the February 27, 2010 Mw 8.8 Maule, Chile earthquake: Geophysical Research Letters, v. 38, p. L09309, 10.1029/2011GL047065. 